\title{
A proposal for the classification of biological weapons sensu lato
}

Lajos ROZSA

MTA-ELTE-MTM Ecology Research Group, Pázmány Str. 1/C, Budapest 1117, Hungary

e-mail: lajos.rozsa@gmail.com

Department of Evolutionary Zoology and Human Biology, University of Debrecen, Debrecen, Hungary

Theory in Biosciences - in press

DOI 10.1007/s12064-014-0204-O

2014 . 


\begin{abstract}
Due to historical and legislation reasons, the category of bioweapons is rather poorly defined. Authors often disagree on involving or excluding agents like hormones, psychochemicals, certain plants and animals (such as weeds or pests) or synthetic organisms. Applying a wide definition apparently threatens by eroding the regime of international legislation, while narrow definitions abandon several important issues. Therefore, I propose a category of 'biological weapons sensu lato' (BWsl) that is defined here as any tool of human aggression whose acting principle is based on disciplines of biology including particularly microbiology, epidemiology, medical biology, physiology, psychology, pharmacology and ecology, but excluding those based on inorganic agents. Synthetically produced equivalents (not necessarily exact copies) and mock weapons are also included. This definition does not involve any claim to subject all these weapons to international legislation but serves a purely scholarly purpose. BWsl may be properly categorized on the base of the magnitude of the human population potentially targeted (4 levels: individuals, towns, countries, global) and the biological nature of the weapons' intended effects (4 levels: agricultural-ecological agents, and non-pathogenic, pathogenic, or lethal agents against humans).
\end{abstract}

\title{
Keywords
}

Psychochemical weapons, Definition, Typology, Classification Biological weapons, Ecological weapons, 


\title{
Historical constraints of defining biological weapons
}

\author{
Origins
}

The history of using pathogens as weapons may well go back to prehistoric or even prehuman ages (Rózsa 2000, 2009). However, the first legal concept of microbial weapons emerged only after WWI when some neutral nations realized that the German embassies in their capitals had been housing mysterious microbiological labs in their buildings during the Great War (Wheelis 1998). Realizing that these labs might had served a hostile role, the League of Nations (1925) proposed a treaty that was signed by most contemporary powers to prohibit the first use of 'Bacteriological Methods of Warfare'. Although viruses had been discovered long before, the brief text did not refer to viruses or virology. Nevertheless, the prohibition of 'bacteriological methods' was usually meant to prohibit the use of all contagious microbial pathogens, whatever their taxonomical positions were, namely viruses, viroids, prions (though the latter two were discovered much later), bacteria, Rickettsiae (that were later identified as a subgroup of bacteria), and even eukaryotic microbes like pathogenic protists and fungi. Thus, instead of 'bacteriological weapons', the term 'biological weapons' came into use as a more appropriate synonym and it was typically meant to be as 'pathogenic microbe weapons'.

The involvement of toxins

Interestingly, several pathogenic bacteria, including highpriority biowarfare agents such as Bacillus anthracis, Vibrio cholerae, Shigella dysenteria among others, actually harm the infected human body by excreting toxins into it. From a purely technical point of view, targeting the enemy either by a purified version of such toxins or by the bacteria that will invade their bodies and then excrete the same toxin may make relatively little medical or legal difference. Accordingly, the next Convention on biological weapons, known as the Biological and Toxin Weapons Convention or BTWC (United Nations1972), further widened the domain of BW by lumping together the categories of microbial pathogenic agents and the toxins of biological origin. This wider concept of bioweapons, now termed as 'bacteriological (biological) agents and toxins' covers pathogenic microbes and a spectrum of biochemical agents that fall somewhere in between the classical categories of microbiological weapons and chemical weapons. The 
purpose of creating such an overlap between biological weapons and chemical weapons was to assure that any 'midspectrum agents' to be potentially discovered in the future would be covered either by the BTWC's domain of validity, or by the Chemical Weapons Convention's (United Nations1992) domain of validity, or by both. And indeed, the subsequent discovery of prions (Prusiner 1982) did not erode the strength of BTWC. The problem here is how to define toxins. Dictionaries traditionally define toxins as poisons of biological origin. Contrarily, toxicology-as a discipline of biomedical science-deals with the effects of both organic and inorganic chemicals. The BTWC mentions 'toxins whatever their origin or method of production' in its Article I. What does it mean? Does it refer to organic poisons exclusively or, alternatively, are inorganic ones also involved? Several biologically produced organic chemicals are not usually classified as toxins because their capability to cause morbidities and fatalities is not selfevident at the dosages we apply them every day. Are the non-lethal psychochemical agents mildly affecting the human psyche, like nicotine and alcohol, toxic? Is the purposeful misuse of alcohol or party drugs (Scott-Ham and Burton 2005; Hall and Moore 2008) an act of biological aggression? Similar questions arise with peptide bioregulators that control aspects of human physiology such as mental processes, mood, consciousness, body temperature ,heart rate, immune responses, sleep etc. If applied in extra quantities, these molecules can modify, debilitate, or even kill humans (Dando 2001; Kagan 2001). Thus regulatory agents of the nervous, endocrine, and immune systems like neurotransmitters, hormones, and cytokines are considered to have a weapon potential (Dando 2011). Many of these materials are used for peaceful medical purposes while they can also turn into substantial weapons if handled with malicious intentions (Atlas and Dando 2006; Tucker 2012).

Are anti-agricultural and ecological weapons included?

Further uncertainty arises about the involvement of antiagricultural agents. Throughout history, biological agents have been repeatedly applied to deny the enemy's access to agricultural crops and livestock, or vital environmental resources such as drinking water or vegetation cover (Whitby 2002; McNeill and Unger 2010). In case of these agents, the line of demarcation between peaceful pest-eradication agents and biological weapons can be quite ambiguous. Taking a plant growth hormone as an example, it is a legal herbicide when applied against weeds causing economic harm to the actor, but it is an ecological weapon when applied against vegetation cover vital for the enemy. Such 
agents are not intended to harm human bodies directly; nevertheless, application of the herbicide 'Agent Orange' during 'Operation Ranch Hand' (1962-1971) unintentionally caused the greatest human morbidity and mortality toll in the history of biological warfare (Galston 2001; Zierler 2011).

Are macrobiological agents included?

Though Article I of BTWC refers to the prohibition of 'microbial or other biological agents...' several scholars interpret 'biological agents' so as to mean pathogenic microbes and microbial toxins that can induce disease in an enemy (Guthrie 2010). Contrary to this view, however, other scholars interpret 'biological' in a much wider sense so as to include all living organisms, such as non-parasitic animals and plants that may possibly be applied as tools of aggression. A wide variety of animals have already been used as potentially lethal weapons of war, terrorism or crime, such as insects (Lockwood 2008), dogs (Maher and Pierpoint 2011), and dolphins (Novosti2012). Take 'pitbulls' as an example, these breeds of dogs (American Pit Bull Terrier, American Staffordshire Terrier, Staffordshire Bull Terrier, Bull Terrier, or any mix of them) were purposefully created by means of artificial selection with the aim to decrease their threshold of aggression and increase attack force. They are readily used as a weapon of crime at present and are also applied by the Police of some countries. Are pitbulls biological weapons? Invasive species have also been considered as potential weapons of antiagricultural aggression, particularly those acting as pests or weeds (Whitby 2002; Roberge 2013).

Microbiological agents are not always easy to separate from macrobiological ones. For example, the infective phase of Ascaris suum - a gut helminth with some biocrime potential (Phills et al. 1972) -is a microscopic egg ( $\max 75 \mathrm{~lm}$ ), while the worm actually develops into a largebodied $(15-45 \mathrm{~cm})$ animal within the bodies of infected humans or animals. Is it included in or excluded from the class of microbiological agents?

Are artificial organisms included?

Moreover, the current rise of synthetic biology poses a new challenge when defining bioweapons. While the traditional interpretation of 'toxin' is a poison of biological origin, BTWC refers to 'toxins whatever their origin'. How to classify viruses of arbitrary 
origin? Modern synthetic biology opens new ways for the chemical synthesis of artificial viruses identical to the natural ones and we cannot exclude the future rise of the synthesis of more complex organisms such as bacteria. If they are produced chemically, are they still meant to be biological weapons? A synthetic poliovirus (Cello et al. 2002) can be treated as identical with a natural one, but how shall we treat synthetic living organisms that have no counterparts in Nature? For example, genetically modified strains of Yersinia pestis carrying genes coding for toxins characteristic to other pathogens (such as diphtheria toxin) or carrying whole viruses (such as Venezuelan equine encephalitis virus) within their cells are 'chimeras' that have no analogues in Nature (Gilsdorf and Zilinskas 2005). Having no copies in Nature are these synthetic structures still classified as 'biological' agents?

Are mock weapons included?

Finally, mock weapons mimicking real ones are usually excluded from the category of BW. However, most weapons and arsenals are actually used to threaten other humans rather than to harm them directly. Aggressors intend to threaten their enemy so as to modify enemy behavior in their own interest. Not only real, but mock weapons may also have some threatening potential. Similarly to toy handguns applied in bank robberies, 'white powder letter' hoaxes mimicking anthrax spore attacks are often used to make the target persons horrified and panicked (Cole 1999). Shall we include such mock bioweapons in the category of BW?

Wide versus narrow interpretations

Applying a wide definition for BW would be detrimental because it would threaten by eroding the regime of international legislation. Taking weeds or white powder letters as an example, one cannot reliably expect to be limited effectively by international law. Such claims would simply erode legislation. Contrarily, however, narrow definitions are disadvantageous because they abandon several important issues and thus one cannot capture all aspects of biological aggression among humans. 


\section{Defining biological weapons sensu lato (BWsl)}

\section{Definition}

Weapons are potential tools or devices of aggression among humans. Some weapons are not used to harm human bodies directly but are implied indirectly by destroying the integrity of their agricultural, ecological or economic environment. They are either tools that humans purposefully design, develop, manufacture and use to harm other humans (directly or indirectly), or at least tools used for threatening other humans with such acts. Actually, most weapons are used to threat, rather than to harm people.

A weapon has a biological character provided that the working principle of its causative agent is based on theorems or principles of biology. All disciplines of biology are included, and microbiology, epidemiology, medical biology, physiology, psychology, pharmacology, toxicology and ecology in particular. Inorganic poisons, however, are excluded from this definition even if their effects are interpreted within toxicology. Typically, BWsl are produced biologically, however, organic or living agents of synthetic (e.g. chemical) origin are also included.

The category of BWsl covers anything that fulfills both of these criteria. Most of the weapons produced, stored or applied by humanity target potential enemies by kinetic energy (from arrows, spears to bullets), radiation (such as thermal or radioactive), explosions releasing chemical or physical (including radiological) energies, or their combinations. Evidently, such weapons are not biological.

In case of agricultural, environmental and medical agents, as mentioned before, the agent itself often has a dual use potential and thus it is purely the purpose of the actor that differentiates a peaceful act from an aggression-this is called the 'general purpose criterion'.

Weaponization of agents

A biological weapon agent, such as the infective form of a pathogen species or a fighting dog, may serve as a crude weapon in itself. Most advanced weapons, however, are technical devices (such as aerosol bombs, etc.) that 'weaponize' a crude agent. The typical purposes of weaponization is to enhance the safe storage of the agents, to ensure its safety to friendly forces, and finally to enable agent delivery to the target. 
The technological details of weaponization often determine the magnitude of the number of people potentially targeted by a biological agent. For example, anthrax spores may either act as a weapon of mass destruction if applied through an aerosol bomb or, alternatively, act as an individual-level biocrime weapon if applied through a single piece of cigarette (Gould and Hay 2006).

\section{A typology of BWsl}

Some former BW typologies

Dando (1994) categorized biological agents from a military point of view taking into account two biological characters; namely the agents' contagious versus non-contagious nature (a capability to establish a self-sustaining epidemic) and their incapacitating versus lethal effects. Subsequently, Rotz et al. (2002) published a categorization that was later also adopted by the Centers for Disease Control of the US Government. This typology is often named the 'CDC categorization' and misinterpreted as a 'categorization of biological weapons' (see e.g. Null 2003; Strelkauskas et al. 2010 among many others). This is misleading for at least two reasons. First, this categorization serves to typify 'biological agents' as opposed to 'biological weapons'. Evidently, agent type does not define weapon type due to potential differences in weaponization. Second, Rotz et al. (2002) categorized bioweapon agents according to one particular point of view, namely their potential within the context of bioterrorism. This was understandable after the 2001 anthrax letter attacks; nevertheless, there may be several other, more relevant perspectives of agent classification. In fact, throughout the past century bioweapon threat and actual usage was scarcer within the context of terrorism than in warfare or crime rendering terrorism utility a secondary aspect (Wheelis and Sugishima 2006).

Further, the US Department of Health and Human Services, National Institute of Allergy and Infectious Diseases (2003) established subcategories for the B and C categories of Rotz et al. (2002) by combining (approximately) the transmission mode of the agent (inhalational, arthropod-borne, food-and waterborne, emerging infectious diseases) and their taxonomic position (toxins, viruses, bacteria, protozoa). 
Apparently, these former typologies aim to capture one or two essential characterssuch as terrorism potential, taxonomical position, or lethality-of agents. It is evident, however, that a categorization of bioweapons based on a typology of agents may not be adequate. It is also clear that the taxonomic position of agents-while interesting for microbiologists-is meaningless for most of the politicians, military, media and the public. Therefore, as an alternative, here I propose that bioweapons' categorization should be based upon their two major attributes understandable to the public; one typifying the weapons' character from a criminal-terrorist-military point of view (the magnitude of human population potentially harmed) and another one typifying the intended bio-medical effect (type of the intended biological harm). Below, both of these features are interpreted in a simple and general sense.

Proposal for a general typology of BWsl

From a military point of view, the approximate criminal, terrorist or military potential of a weapon can be roughly characterized on the base of the potential magnitude of the target population, i.e. the number of people potentially harmed.

Type A Individuals level. These weapons may effectively target one or several individuals. The effect magnitude ranges from 1 up to several hundred $(<1,000)$ of target persons.

Type B Towns level. These weapons may effectively target a larger group of humans, such as a village or town society with an effect magnitude of harming about 1,00o to several 100,000s ( $<1$ million) target persons.

Type C Countries level. Such weapons may effectively target the human population of large countries or even subcontinents. The magnitude potentially harmed ranges from 1 million to several 100 millions ( $<1$ billion).

Type D Global level. Theoretically, such weapons are designed and developed to harm a large proportion of humankind ( $>1$ billion persons).

From a biomedical point of view, a weapon can be characterized by the types of intended destructive biological effects potentially achieved by the application of BWsl.

Type 1 Anti-agricultural or ecological destruction. These weapons are not intended to harm human bodies directly. They are designed, developed and applied with the 
purpose of destroying the enemy's capability to produce or access food, drinking water or habitable environment.

Type 2 Non-pathogenic modifiers of human bodily functions (including psyche, emotions, behavior, immunology, and physiology). These weapons can transform certain functions of the human body without typically and intentionally causing disease in a traditional medical sense.

Type 3 Pathogenic weapons causing non-lethal human diseases. When applied in appropriate dosages, these weapons cause human diseases in a traditional medical sense while they are not intended to be lethal to humans.

Type 4 Lethal biological weapons. When applied in appropriate dosages, these weapons are potentially lethal to a proportion-even if usually much $<100 \%$-of humans targeted.

The above list of biological potentials is more-or-less directional. Weapons classified into a higher category are also capable to elicit some or all the effects characteristic to the lower categories. Contrarily, lower category weapons are not typically capable to elicit the effects characteristic to higher categories. Taking pathogenic weapons (type 3) as an example, they do not only cause human diseases, but also often elicit other modifications of target persons' psychological or physiological functions, and possibly even agricultural and environmental damages. On the other hand, when applied in the appropriate quantities or dosages, they do not cause human mortality. of human population

Categorizing weapons, arsenals, or events

The essence of the present proposal is to categorize BWsl on the base of their approximate magnitude of potential effectiveness (in a criminal, terrorism or military sense) combined with their intended (maximal) biological effects. E.g. a 'white powder letter' containing totally harmless material (say, flour) is an individual level nonpathogenic modifier of human emotions (A2 category). The former type E120 tularemia spray bomblet of the US Army was approximately 'towns level lethal (B4)' category weapon referring to its presumed capability to kill several thousands of people, at least if applied in cities (Dennis et al. 2001; van Courtland Moon 2006). This does not exclude, 
evidently, a capability to elicit weaker (biologically lower level) harms (such as agricultural loss) affecting the life of a much wider circle of people.

Practically, the categories outlined above are not only suitable to typify single weapons, but biological arsenals or bioaggression events (biocrime, bioterrosism or biowarfare events) may be classified along the same typology as well. For example, the Imperial Japanese Army's biological aggression carried out in Manchuria (1937-1945) probably fell into the 'countries level and lethal ( $\left.\mathrm{C}_{4}\right)$ ' category (Harris 2002). Though global-scale lethal bioweapons apparently have not been created up to present, taking the whole Soviet bioweapon arsenal of the late 1980 s or early 1990 s together could have matched the 'D4' category (Hart 2006). Naturally, while applying this categorization, it is essential that future authors must clarify whether they speak about individual weapons, arsenals or events.

When typifying magnitude, the number of target persons potentially affected is judged on a worst-case scenario assessment. A weapon that can kill millions of people in case of applying it in densely populated urban areas falls into the ' $\mathrm{C} 4$ ' category even though it would cause much less fatalities if applied in scarcely populated rural areas.

Obviously, a weapon of large spatial distribution of potential impact is expected to harm more people than another one. Please note, however, that the temporal duration of impacts is another, though often overlooked, influential determinant of the number of humans harmed. Taking an induced influenza outbreak as an example, it is easy to see that its effects are predictably short-termed, lasting for a few weeks or months. On the other hand, the genotoxic pollution of the environment (as it occurred accidentally during the US herbicide warfare in Vietnam, 1962-1971) may exemplify an extreme temporal duration lasting through several decades or more (Galston 2001; Zierler 2011). Thus, any weapon's potential target population size is to be judged by considering both the spatial distribution and temporal duration of potential impacts.

\section{Conclusion}

Former authors provided a variety of narrower or wider definitions for BW. Narrow definitions did not cover several organisms or toxins of biological nature or biological 
origin that can potentially be utilized as weapons, such as hormones, police dogs etc. Wide definitions, on the other hand, could have appeared like claims that potentially threat by the erosion of the regime of BTWC.

Therefore, I proposed here a category named biological weapons sensu lato (BWsl), to address any biological tools of human aggression without claiming that all of them should necessarily be considered within the legal framework of BTWC. Rather, the present concept and typology of BWsl serves a purely scholarly purpose. Studying the

political, criminal, behavioral, sociological or historical aspects of biological aggression needs much wider categories than those outlined by international legislation.

Given that BWsl covers a wide variety of bioaggression tools ranging from trivial white powder letters to aerosol bombs having a mass destruction potential, it is essential that we apply a typology to categorize fundamentally different weapons. For this purpose, above I proposed a categorization based on (1) the magnitude of the human population potentially targeted (4 levels) and (2) the biological nature of the weapons' intended effect (4 levels). Naturally, a similar typology is also applicable to characterize either whole arsenals of BWsl or bioaggression events. This will hopefully contribute to clarifying future scholarly discussion on biological aggression without causing confusion in international legislation related to BW.

\section{Acknowledgments}

This research was supported by the EU and Hungary, co-financed by the European Social Fund in the framework of TÁMOP 4.2.4. A/2-11-1-2012-0001 'National Excellence' Program.

\section{References}

Atlas RM, Dando M (2006) The dual-use dilemma for the life sciences: perspectives, conundrums, and global solutions. Biosecur Bioterror 4:276-286. 
Cello J, Paul AV, Wimmer E (2002) Chemical synthesis of Poliovirus cDNA: generation of infectious virus in the absence of natural template. Science 297(5583):1016-1018. Cole LA (1999) Risks of publicity about bioterrorism: anthrax hoaxes and hype. Am J Infect Control 27:470-473.

Dando MR (1994) Biological warfare in the 21st Century. Brassey's, London Dando M (2001) Genomics, bioregulators, cell receptors and potential biological weapons. Def Anal 17:239-257.

Dando M (2011) Advances in neuroscience and the Biological and Toxin Weapons Convention. Biotechnology Research International, Article ID 973851.

Dennis DT, Inglesby TV, Henderson DA, Bartlett JG, Ascher MS, Eitzen E et al (2001) Tularemia as a biological weapon: medical and public health management. JAMA 285:2763-2773.

Galston AW (2001) Falling leaves and ethical dilemmas: Agent Orange in Vietnam. In: Galston AW, Shurr EG (eds) New dimensions in bioethics: science, ethics and the formulation of public policy. Springer, Dordrecht, pp 109-124.

Gilsdorf JR, Zilinskas RA (2005) New considerations in infectious disease outbreaks: the threat of genetically modified microbes. Clin Infect Dis 40:1160-1175.

Gould C, Hay A (2006) The South African biological weapons program. In: Wheelis M, Rozsa L, Dando M (eds) Deadly cultures: biological weapons since 1945. Harvard University Press, Cambridge, pp 191-212.

Guthrie R (2010) Effectiveness of international efforts to control biological weapons: activities of the European Union and the limits of regime theory. Dissertation, University of Bath

Hall JA, Moore CBT (2008) Drug facilitated sexual assault-a review. J Forensic Leg Med 15:291-297.

Harris SH (2002) Factories of death: Japanese biological warfare, 1932-1945, and the American cover-up. Routledge, New York.

Hart J (2006) The Soviet biological weapons program. In: Wheelis M, Rozsa L, Dando M (eds) Deadly cultures: biological weapons since1945. Harvard University Press pp 132-156. 
Kagan E (2001) Bioregulators as instruments of terror. Clin Lab Med 21:607-618.

League of Nations (1925) Protocol for the prohibition of the use in war of asphyxiating, poisonous or other gases, and of bacteriological methods of warfare.

http://disarmament.un.org/treaties/t/1925/text. Accessed 19 May 2014.

Lockwood JA (2008) Six-legged soldiers: using insects as weapons of war. Oxford University Press, New York.

Maher J, Pierpoint H (2011) Friends, status symbols and weapons: the use of dogs by youth groups and youth gangs. Crime Law Soc Change 55:405-420.

McNeill JR, Unger CR (2010) Environmental histories of the Cold War. Cambridge University Press, Cambridge.

Null G (2003) Germs, biological warfare, vaccinations: what you need to know. Seven Stories, New York.

Phills JA, Harrold AJ, Whiteman GV, Perelmutter L (1972) Pulmonary infiltrates, asthma and eosinophilia due to Ascaris suum infestation in man. New Eng $J$ Med 286:965-970.

Prusiner SB (1982) Novel proteinaceous infectious particles cause scrapie. Science 216(4542):136-144.

RIA Novosti (2012) Ukraine brings back naval killer dolphins.

http://en.rian.ru/military_news/20121011/176548999.html. Accessed 19 May 2014.

Roberge LF (2013) Analysis of introduced species as a form of biological weapon: part 1-theory and approaches. Biosafety 2:107.

Rotz LD, Khan AS, Lillibridge SR, Ostroff SM, Hughes JM (2002) Public health assessment of potential biological terrorism agents. Emerg Infect Dis 8:225-230.

Rózsa L (2000) Spite, xenophobia, and collaboration between hosts and parasites. Oikos 91:396-400.

Rózsa L (2009) The motivation for biological aggression is an inherent and common aspect of the human behavioural repertoire. Med Hypotheses 72:217-219.

Scott-Ham M, Burton FC (2005) Toxicological findings in cases of alleged drugfacilitated sexual assault in the United Kingdom over a 3-year period. J Clin Forensic Med 12(4):175-186. 
Strelkauskas AJ, Strelkauskas J, Moszyk-Strelkauskas D (2010) Microbiology: a clinical approach. Garland Science, New York.

Tucker JB (2012) Innovation, dual use, and security: managing the risks of emerging biological and chemical technologies. MIT Press, Cambridge.

United Nations (1972) Convention on the prohibition of the development, production and stockpiling of bacteriological (biological) and toxin weapons and on their destruction.

http:// www.opbw.org/convention/conv.html. Accessed 5 May 2014.

United Nations (1992) Convention on the prohibition of the development, production, stockpiling and use of chemical weapons and on their destruction. http://www.opcw.org/chemical-weapons-convention. Accessed 19 May 2014.

US Department of Health and Human Services, National Institute of Allergy and Infectious Diseases (2003) Biodefense research agenda for category B and C priority pathogens. NIH Publication No.03-53152003. http://www.niaid.nih.gov/topics/BiodefenseRelated/Biodefense/Documents/categoryb andc.pdf. Accessed 19 May 2014.

van Courtland Moon JE (2006) The US biological weapons program. In: Wheelis M, Rozsa L, Dando M (eds) Deadly cultures: biological weapons since 1945. Harvard University Press, Cambridge MA, pp 9-46.

Wheelis ML (1998) First shots fired in biological warfare. Nature 395(6695):213.

Wheelis M, Sugishima M (2006) Terrorist use of biological weapons. In: Wheelis M, Rozsa L, Dando M (eds) Deadly cultures: biological weapons since 1945. Harvard University Press, Cambridge, pp 284-303.

Whitby SM (2002) Biological warfare against crops. Palgrave, Hampshire.

Zierler D (2011) The invention of ecocide: Agent Orange, Vietnam, and the scientists who changed the way we think about the environment. University of Georgia Press, Athens. 